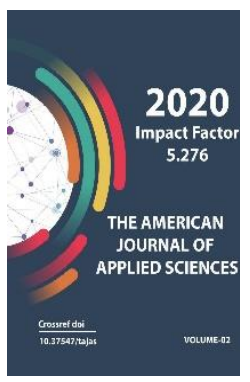

\title{
Dynamics Of Change Of Seed Fluff After Germination Process
}

Karshiyev Olim Namozovich

Assistant At The Termez Branch Of The Tashkent State Technical University Named After Islam Karimov, Uzbekistan

\section{ABSTRACT}

Residual fiber in the fiber-separated seeds reduces the efficiency of fluff separation in linter machines, and the process of fluff separation is disrupted as a result of the clogging of the fibers into the saw teeth. Therefore, theoretical, practical research and creation of a device for separation of fibers from residual fluffy seeds before the lintering process is relevant.

\section{KEYWORDS}

Cotton, fiber, linter, seed, enterprise, working chamber, grate.

\section{INTRODUCTION}

When the cotton is brought to the main building of the ginnery, the seed cotton is delivered flat to the gin's working chamber, then to the supply mine, which is mounted on each gin with a separator and distribution conveyor.

The seed cotton that falls into Jin's working chamber (Fig. 1.1) is picked up by a saw 4 teeth rotating on the side of the seed comb 1 and dragged along the $A B$ arc to bring it to the column 5 . The cotton swabs attached to the teeth stick to the other cotton swabs and pull them as well, all the cotton swabs in the chamber begin to spin. Thus, a cotton roller with a seed that rotates in the opposite direction to the saw is formed, which 
continuously supplies the saw teeth with cotton fiber [1].

The fibers attached to the saw teeth are passed between the columns, and the seeds are unable to pass, so that the fibers are separated from the seeds. The fibers in the saw teeth are separated by a stream of air coming out of the nozzle and transferred to a common fiber traction tube. Since the width of the holes in the working part of the columns is not larger than $3.2 \mathrm{~mm}$ (the size of the smallest seed), the seed cannot pass through, the rotating seed is attached to the cotton roller and continues to rotate until all the fibers are separated.
The seeds, separated from all the fibers, lose their ability to cling, the seed separates from the cotton roller and falls to the surface of the column, and then down the ridge between the seed comb and the column. The degree of fluffiness of the seeds coming out of the jinn is controlled by changing the gap between the comb and the chisel.

The continuous supply of seed cotton to the working chamber of the jinn, and the uninterrupted exit of the seeds separated from the jinn and fiber, ensure the uninterrupted operation of the arali jinn [2].

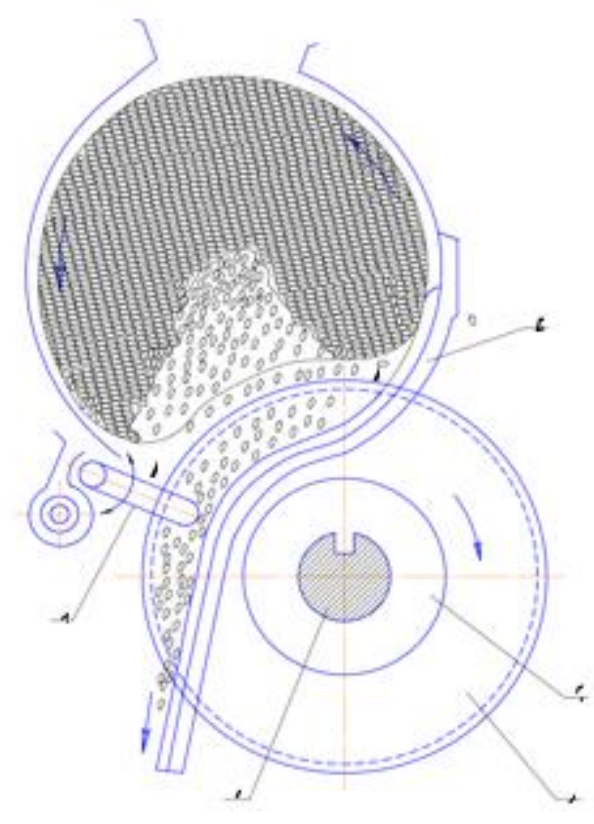

Figure 1.1. The effect of the saw on the seed cotton roller.

The shape of the working chamber is of great importance for the operation of the jinn, which has a great influence on its productivity, the power required, the quality of the fiber produced, and the fineness of the seed produced by the jinn.

The working chamber of the saw blade (Fig. 1.2) consists of the roof beam 1 , the rafters 2 , the lower rafter beam 3, the seed comb 4, the lower apron 5 and the front apron 6 . The saw discs enter the chamber $47-52 \mathrm{~mm}$ from the holes of the saw blades, and the input arc of the saw forms $A V$.

The design of the working chamber must meet the following technological requirements: its parts must not cause defects in the cotton and damage the seeds, the shape of the chamber should not impede the rotation of the seed cotton as much as possible. Obstacles to the arrival of seed cotton to the chamber, to the 
emergence of fiber and seeds should be as low as possible.

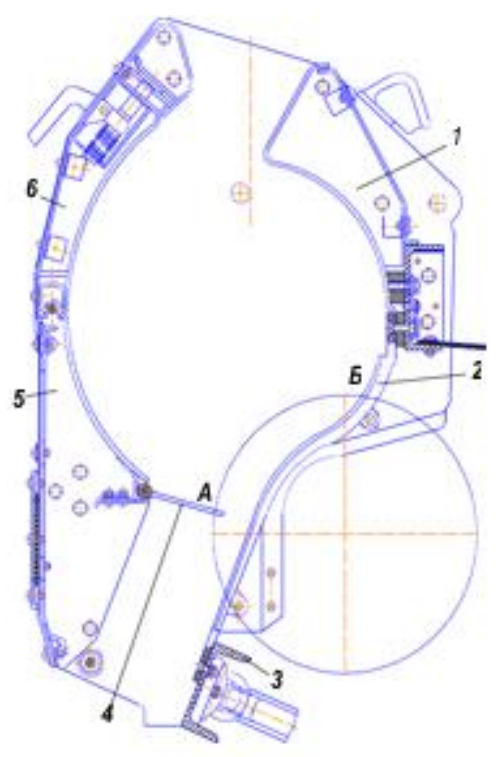

Figure 1.2. Jin's working camera.

1st upper beam, 2nd column, 3rd lower beam, 4th seed comb, 5th lower apron, 6th top apron, The following equation has been determined for the stable ginning process

$$
P=Q A / t_{\bar{y} p}
$$

where the performance of the P-working chamber on the fiber; Q-seeded cotton mass; $A$ constant characteristic of the A-jinning process; the average stay time of the fiber and seed in the mesh-working chamber.

According to this formula, the working productivity of the working chamber can be increased by increasing the seed cotton mass in the chamber or by reducing the average time the seed with fiber in the chamber. To increase the seed cotton mass, it is necessary to increase the cross-section of the chamber, which (when the saw diameter does not change) increases the friction force of the seed cotton roller on the chamber walls and prevents its rotation. In the seed cotton roller in the chamber, the seeds, which are ready to be completely separated from the fibers, make up more than 50 percent of the mass of the roller. Therefore, the productivity of the working chamber can be increased only by reducing the average stay time of the seed in the chamber [3].

When the diameter of the saw blade is $320 \mathrm{~mm}$ and the rotational frequency is $730 \mathrm{~min}-1$, the linear velocity of the saw tooth is $12 \mathrm{~m} / \mathrm{s}$. The rotation frequency of the seed cotton roller ranges from 100 to $130 \mathrm{~min}-1$ depending on the shape of the chamber and the operation of the gin. If we assume that the conditional diameter of the seed cotton roller in the chamber is equal to the diameter of the saw discs, the linear velocity of the cotton piece located on the surface of the seed cotton roller will be $2 \mathrm{~m}$ / s. Hence, the relative velocity of the saw tooth cutting into the seed cotton mass is $10 \mathrm{~m} / \mathrm{s}$.

The shear of the seeded cotton roller fits the shape of the working chamber and is complex. The speed of the seeded cotton swab hanging over the AEB arc is close to the linear velocity 
of the saw tooth $(12 \mathrm{~m} / \mathrm{s})$. In zone $B$, the cotton pieces are exposed to stationary columns reduces the speed to $1.1-1.5 \mathrm{~m} / \mathrm{s}$. In the BVG arc section, their velocity increases to $2.0-2.2 \mathrm{~m} / \mathrm{s}$. In the GDA arc part, the velocity of the seed cotton increases again to $2.5-2.8 \mathrm{~m} / \mathrm{s}$, and this velocity is added again in the seed comb zone.

The fact that the linear velocity of the seed cotton pieces varies in this order on the surface of the seed cotton roll indicates that there is an internal displacement of the cotton pieces forming the seed cotton roll and the dynamics of the cotton pieces in the working chamber is more complex [4].

The main working body of saw blades is made of special steel (carbon steel U8G according to GOST 2052 or cold-drawn heat-treated steel according to GOST 1435).

The dimensions and parameters of the gin saw must comply with the requirements specified in GOST 1413. The saw tooth consists of two edges, the anterior or working edge (relative to the rotating side of the saw) and the intersection of the rear edge or shoulder edges. The tooth hangs the fibers with its front edge, passes them through the coil, and brings them into the air stream. The edges at the bottom of the tooth are rounded with a radius of $0.5-0.1 \mathrm{~mm}$ to avoid excessive stress on the metal [5]. The grating grate (Fig. 1.3) is one of the most important parts of the saw gin working chamber. It allows the saw discs to move freely between the chimneys to the working chamber, and the fibers attached to the saw teeth to be removed freely after separation from the seeds.

The grate grate 1 is made up of some grate bars, which together with the roof beam 2 form the profile of the working chamber. The columns are attached to the upper beam 3 and lower beam 4 with special screws. Columns are made of

cast iron SCh-15-32. Their work surfaces are shaped on special machines. The surface of the column is hardened by heat treatment.
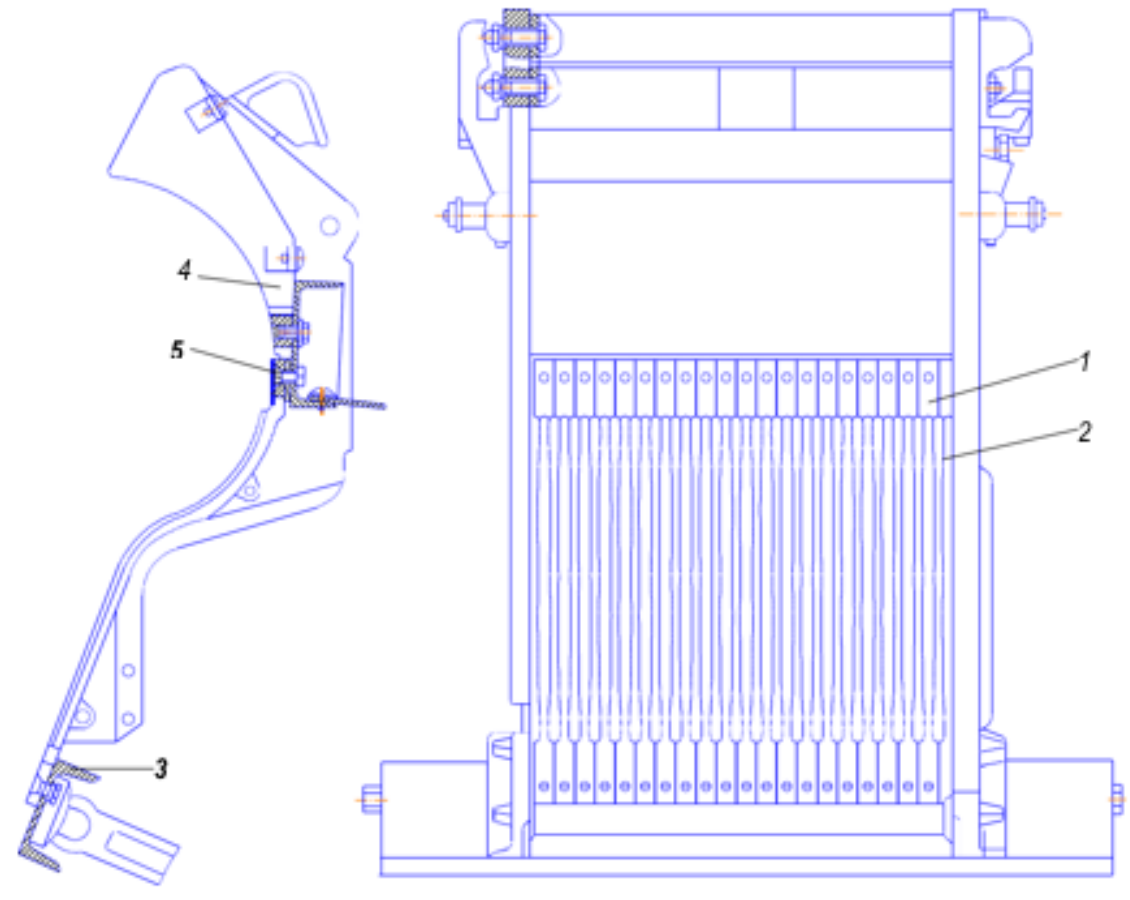

Figure 1.3. The scheme of the grate grate. 
For normal operation of saw blades, the working surface of the grate should be flat, without dents, and the distance between the grate should be $2.8-3.2 \mathrm{~mm}$ in the working zone, and $4.5-5 \mathrm{~mm}$ at the top and bottom. The number of columns in a grid is one more than the number of saws on the shaft, two narrow columns are set aside, and the remaining normal widths are intermediate columns.

It is necessary to maintain the distance between the seed comb and the colostrum to reduce the amount of residual hairy seeds after sawing. Through the position of the seed comb, the seed fluff coming out of the working chamber is adjusted.

The initial processing of cotton consists of the preparation, storage, transfer to production, drying, cleaning, separation of fiber from cotton seeds (ginning), separation of lint (lintering), cleaning and spinning of fibrous products. In addition to these basic processes, there are auxiliary equipment that connects the processes, aspiration and polluted air purification systems. Analysis of advanced technological processes of primary processing of cotton in the world shows that only in Uzbekistan in the technological process after the ginning process lintering of cotton seeds is carried out in one enterprise.

According to the coordinated technology of primary processing of cotton [28], the main processes in ginneries in Uzbekistan consist of nine stages. When processing high-grade cotton, the productivity of the enterprise on raw materials is $7000 \mathrm{~kg} / \mathrm{h}$.

The products obtained by technological processes and the ratio of power installed in the equipment for the production of these products - are shown in the table and the diagram built on it.

When we analyze this diagram, we see that in the lintering of cotton seeds, the amount of power set for cotton production is relatively high compared to other products, and therefore the energy capacity of cotton production is several times higher than that of other products.

After the separation of fiber from cotton, about 4.5 tons of seeds in the first industrial grade cotton will be sent to the lintering process. Currently, 5LP linters are used in ginning plants to separate lint from seeds. RNS regenerators are used to capture the seeds in the residual hair follicles in front of the liners [6].

The seed productivity of this linter at the first fluff separation (when the fluff separation is $2.8-3.0 \%$ ) is $2000-2300 \mathrm{~kg} / \mathrm{h}$, in the second fluff separation (when the fluff separation is 3.0$3.2 \%$ ) it is $1500-1700 \mathrm{~kg} / \mathrm{h}$. According to the coordinated technology of cotton raw material processing [30], 8-12 5LP linters are installed in cotton processing plants equipped with twosaw gin.

\section{Table 1.1.}

\section{The product obtained in the technological process of primary processing of cotton and the}

$$
\text { installed capacity. }
$$

\begin{tabular}{|c|c|c|c|}
\hline & $\begin{array}{r}\text { Quantity } \\
\text { of product } \\
\text { Technological } \\
\text { to be }\end{array}$ & $\begin{array}{c}\text { Installed } \mathrm{n} \\
\text { power, }\end{array}$ & $\begin{array}{c}\text { Ratio of installed power } \\
\text { and output (relative } \\
\text { installed energy) }\end{array}$ \\
\hline
\end{tabular}




\begin{tabular}{|c|c|c|c|}
\hline & $\begin{array}{c}\text { obtained, } \\
\text { tons }\end{array}$ & & \\
\hline $\begin{array}{c}\text { To the } \\
\text { production } \\
\text { signal }\end{array}$ & 7 & 82.5 & 11.8 \\
\hline Drying & 7 & 85 & 12.1 \\
\hline Тозалаш & 7 & 148 & 21.1 \\
\hline Cleaning & 2.45 & 160 & 65.3 \\
\hline Lintering & 0.4 & 286 & 715.0 \\
\hline Fiber cleaning & 2.43 & 22 & 9.1 \\
\hline Fluff cleaning & 0.39 & 5.5 & 14.1 \\
\hline Fiber staining & 2.43 & 100 & 41.2 \\
\hline Feather fluff & 0.39 & 100 & 256.4 \\
\hline
\end{tabular}

If we take into account the emphasized work efficiency of the 5LP linter on the seed, 3-4 5LP linters would be sufficient to separate the fluff from the $4500 \mathrm{~kg}$ of seed after the two sawdust. However, in practice, observations at ginneries (Surkhandarya and Syrdarya ginneries) revealed that despite the installation of 8-12 5LP linters at two 4DP-130 or two DPZ ginneries, the seeds were piled up in stock due to low seedling productivity. In this case, the fiber separation process is stopped, and the wool separation from the stockpiled seeds is done for 1-2 hours, after which the fiber separation process from the cotton is continued. This leads to a decrease in the overall production efficiency of the enterprise.

In order to identify problems in the separation of down from cotton seeds, the following practical research was conducted in the production environment. 10 linters installed at
Sayhunabad ginnery from seeds, linter working chamber and

samples were taken after the fluff separation process. All linters the seed productivity and the amount of seed in the linter working chamber were measured. The research was conducted during the processing of the "Sultan" selection variety of cotton.

The results of the experiment show that there is a big difference between the performance of the 5LP linter in the scientific literature on performance and its performance in practice.

Theoretical sources state that the productivity of seed sowing is $1500-2000 \mathrm{~kg} / \mathrm{h}$ in the change of industrial varieties, the productivity of wool is $35-50 \mathrm{~kg} / \mathrm{h}$, in practice the productivity of seed is $433.4 \mathrm{~kg} / \mathrm{h}$, the average yield of wool is $18,1 \mathrm{~kg} / \mathrm{h}$. 
In order to increase the efficiency of fluff separation from cotton seeds, research should be conducted on the development of technology that reduces the yield time of fluffy seeds in the linter working chamber, provides a percentage of fluff yield and moderate fluff of the emerging seeds.

\section{CONCLUSION}

At present, the productivity of $5 \mathrm{LP}$ linter equipment for seed transplanting and fluff separation does not correspond to the indicators noted in the scientific literature. The reason is that these figures are shown for the technological process of the $80-90$ s of last century. During this period, the stages of processing and selection of processed cotton changed. Therefore, it is necessary to study the fluff separation technology for the updated condition.

\section{REFERENCES}

1. Jabborov G'.J. and others. Technology of processing of raw cotton. // -Tashkent. "Teacher" 1987

2. Zikriyoev E.Z. Preliminary processing of raw cotton. // Tashkent, "Labor", 2002.

3. Spravochnik po pervichnoy obrabotke xlopka. 1-2 books. "Mexnat", Tashkent, 1994

4. E.. Z. Zikriyoev. Pervichnaya perepabotka xlopka-syrtsa. Tashkent "Mexnat" -2002.

5. Spravochnik po pervichnoy obrabotke xlopka. V 2-x knigax. - T .: Mexnat, 1994, K.1574

6. 7. Tadjibaev M.A. «Razrabotka ustanovki dlya podgotovki xlopkovyx semyan $k$ pererabotke $\mathrm{s}$ tselyu uluchsheniya kachestvo linta i semyan. Diss. Kand. Techn. Science. T., 1993.

7. Q. Sabirov's dissertation "Development of high-efficiency, step-by-step ginning and Intering technological process". $2009 \mathrm{y}$ 